\title{
A new genus of Philorheithridae (Trichoptera) from Madagascar
}

\author{
JOHN S. WEAVER III ${ }^{1}$, FRANÇOIS-MARIE GIBON ${ }^{2} \&$ PAVEL CHVOJKA ${ }^{3}$ \\ '29 Hazen Drive, Department of Agriculture Lab, Concord, NH 03301, USA. E-mail: jweaver@agr.state.nh.us \\ ${ }^{2} I R D$, antenne au MNHM, CP 26, 43 rue Cuvier, 75005, Paris, France \\ ${ }^{3}$ National Museum, Department of Entomology, Kunratice 1, 14800 Praha 4, Czech Republic
}

\begin{abstract}
Afrorheithrus genus novum and three species (Afrorheithrus fallax sp. nova, A. mirus sp. nova, A. admirabilis $\mathbf{s p .}$ nova) of the family Philorheithridae (Trichoptera) are described from Madagascar, representing the first described philorheithrids from the Afrotropical Region.
\end{abstract}

Key words: Afrorheithrus, Africa, caddisflies, taxonomy

\section{Introduction}

The examination of caddisfly material from Madagascar has revealed a new genus and some new species of Philorheithridae. Depositories of material examined are abbreviated as follows, MNHN, Muséum National d'Histoire Naturelle, Paris; NMPC, National Museum, Praha; USNM, National Museum of Natural History, Smithsonian Institution, Washington, D.C.

\section{Philorheithridae Mosely}

The philorheithrids are a relatively small family, represented by eight described genera, six from Australasian Region (Philorheithrus Hare, Aphilorheithrus Mosely, Tasmanthrus Mosely, Austrheithrus Mosely \& Kimmins, Kosrheithrus Mosely \& Kimmins, Ramiheithrus Neboiss), and two from the temperate Neotropical Region (Psilopsyche Ulmer and Mystacopsyche Schmid). The new genus described herein, is the first philorheithrid recorded from the Afrotropical Region. The characteristics of the family have been described by Mosely \& Kimmins (1953), Schmid (1955), and Neboiss (1977, 1991). Males and females have been described for all genera except Ramiheithrus, for which females are unknown.

Diagnosis. We agree with Parker and Wiggins (1987) that the Philorheithridae are closely related to the Odontoceridae. Adults of both families have unique modifications in the anterior wings, having a slender vein along the posterior margin, but we are not certain that it is a true vein. It was observed in Philorheithridae and Odontoceridae by Schmid $(1964,1980)$ and referred to it as the "post anale" vein. The anterior wing is also modified by having the posterior margin slightly recessed and the anal lobe small but conspicuously thickened. All of these characters together would appear to increase the strength of the posterior margin. This characteristic appears to be a strong synapormorphy, supporting monophyly of the Philorheithridae and Odontoceridae.

Reliable characteristics that may distinguish the Philorheithridae and the Odontoceridae from each other are not apparent to us at this time. A more through study of each group would be required to answer this ques- 
tion, and so the following diagnosis is tentative. Most of the Philorheithridae differ from the Odontoceridae by having 1) pronotum with median and lateral setal warts present (not fused together as they appear to be in Odontoceridae); 2) adult male and female maxillary palps each with first segment bearing an apicomesal nodule; 3) anterior wings each with venation more complete, having forks 1, 2, 3, 5 usually present in males, and forks $1-5$ in females; 4) anterior wings each with apical margin between forks 3 and 5 , and posterior margin slightly concave; 5) anterior wings each with prominent basal lobe of posterior margin covered with numerous microtrichia on the upper surface; and 6) female genitalia with lateral appendages reduced.

Adult. Ocelli absent. Maxillary palps 5-segmented, except 4-segmented in males of Tasmanthrus, and 3segmented in Austrheithrus. Five genera (Philorheithrus, Aphilorheithrus, Tasmanthrus, Kosrheithrus, and Mystacopsyche) unique among Trichoptera in having pair of pilifers arising ventrally from male frons (Mosely \& Kimmins 1953; Schmid 1955). Fore, middle, and hind leg spur formula is 2, 4, 4. $R_{1}$ joins $R_{2}$ apically in anterior wings of males and females except for Afrorheithrus; length of 1A usually atrophied in most genera except Philorheithrus and Afrorheithrus; and jugal lobe reduced. Secondary sexual dimorphism expressed in venation of anterior wings; male with forks 1, 2, 3, and 5; females with forks 1-5, except fork 4 absent in Kosrheithrus. Posterior wings of males and females with forks 1, 2, 5 present, except fork 3 also present in females of Aphilorheithrus. Abdominal sternite $\mathrm{V}$ with scent gland inconspicuous, apparently absent. A midsternal process is present on abdominal segment VI and/or VII in males and females of most genera.

A description of crypsis by the adult of Philorheithrus agilis was given by Hudson (1904) in the original species description:

"It delights to rest on overhanging twigs, situated close to the most rapid-running water. While thus resting it is extremely difficult to see, the antennae being placed close together and thrust straight in front of the insect, whilst the wings are closely folded around the body. When in this position the creature must resemble a small stick, but if it be too closely approached it dashes with amazing rapidity into the water, floats down the stream for a considerable distance, and eventually seizes hold of some similar twig at the water=s edge, where it reposes as before. These peculiar habits are no doubt protective, and certainly render both the detection and capture of the insect a most difficult matter. Its movements are, in fact, of such a sudden and bewildering nature that the collector is often taken by surprise and loses his quest."

Another philorheithrid, Aphilorheithrus stepheni Mosely, was observed and photographed in a similar cryptic, stick-like posture by Arturs Neboiss (pers. com.). An illustration based on this photograph was made by Charles McCubbin for the dust jacket of A Taxonomic and Zoogeographic Study of Tasmanian Caddisflies by Neboiss (1977). This illustration is reproduced herein (Fig. 1) with the kind permission of Neboiss. We believe that this type of cryptic behavioral characteristic is characteristic for most philorheithrids, especially those that have their anterior wings obliquely truncated.

Larva. The larva of Philorheithrus agilis was described by Hudson (1904) and redescribed by Cowley (1978), who mentioned that the larvae dwell in fast flowing streams, and construct cylindrical cases that are tapered slightly apically, composed of small stones, and lack posterior partitions. The larvae of Psilopsyche and Mystacopsyche have not been described, but Flint et al. (1999) mentioned that they "live in rivers and small streams, often in the sandy bottom."

\section{Afrorheithrus genus novum}

\section{Type species: Afrorheithrus fallax sp. nova}

Diagnosis. Among the other philorheithrid genera known, Afrorheithrus appears to be most similar to Ramiheithrus, but differs by having male antenna filiform, and male anterior wing with $\mathrm{R}_{1}$ and $\mathrm{R}_{2}$ separate (not 
fused together apically). The anterior wing of the female is unique in having forks 3 and 4 both petiolate; anterior wing of male and female is unique in having $A 1$ long and $R_{1}$ free apically (not fused with $R_{2}$ or $S c$ ). Spur formula: 2, 4, 4 in both sexes.

Adult. Head (Fig. 3) with antennal warts small, nearly circular and between bases of antennae; occipital warts oblong, aligned in $\mathrm{V}$-shaped formation, postorbital warts present. Frons with notch between bases of antennae, and pair of anterolateral warts each triangular and adjacent to eye; hypomedial warts small and just above ventral margin. Antennae (Fig. 2) with each segment of flagella slightly capitate, having apical portion broader than basal portion, with base fitting into cuplike depression in apex of preceding joint with base of "cup" set obliquely. Maxillary palps 5-segmented, each first segment with small apicomesal nodule bearing tuft of thickened setae. Thorax (Fig. 3, 4), pronotum mesal area is recessed and very dark brown, median warts bulbous, protruding dorsomesally, sometimes so extensively that they almost meet each other dorsally and overlapping mesal surface of pronotum; lateral warts ovate with anterior portion tapered. Mesonotum with scutal warts sometimes each teardrop-shaped with anterior portion tapered anteriorly, or elliptical; scutellal warts small and nearly circular. Anterior wings brown and irregularly speckled.

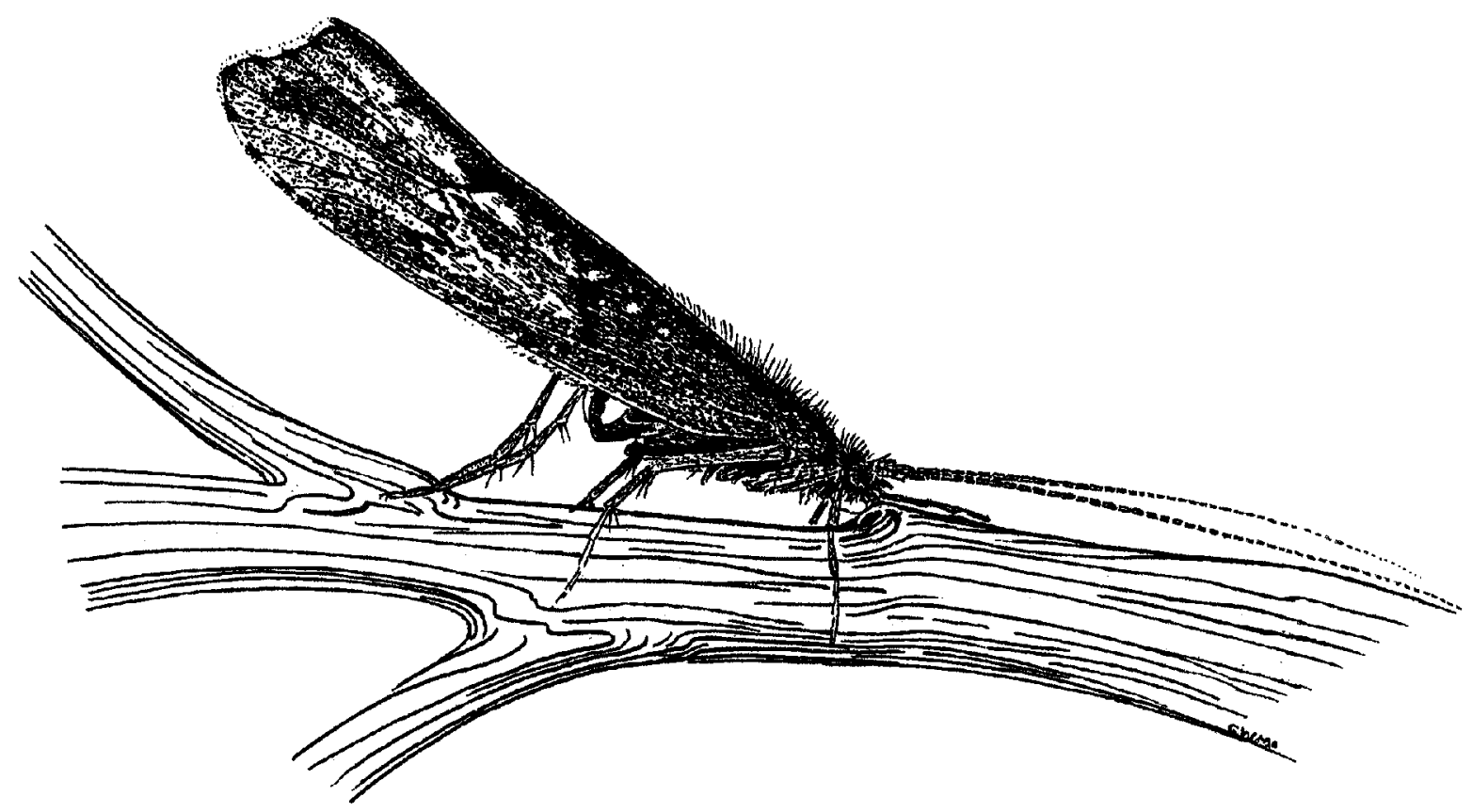

FIGURE 1. Aphilorheithrus stepheni Mosely: Habitus of adult in cryptic, stick-like posture, original figure illustrated by Charles McCubbin based on photograph by Arturs Neboiss.

Male. Maxillary palp 5-segmented, frons with pilifers absent. Anterior wing (Fig. 6) with forks 1, 2, 3, 5 present; R1 not fused with Sc or R2 apically, and A1 long. Posterior wing with forks 1, 2, 5 present; venation similar to that of female, except additional crossvein c-sc just basal to sc-r halfway between base of fork 1 and sc-r. Abdomen segments VI and VII each without midsternal process. Genitalia generally similar to those of Aphilorheithrus and Psilopsyche. Segment IX with dorsoanterior margin nearly straight and vertical, but slightly slanted; ventroanterior margin incised in lateral view; tergum IX short in length, being shortest in middle in dorsal view. Preanal appendages together ligulate in dorsal view, large, broader in dorsal view than in lateral view, with basal margins occupying nearly entire dorsoposterior margin of segment IX; long, extending posterad further than other genitalic processes; each process with lateral and mesal margins nearly straight and parallel, apicomesal margins angled, and apicolateral margin curved. Segment X smaller and shorter in length than preanal appendages, with apicodorsal surface bearing many short teeth, lower than preanal appendages, and higher than phallus. Inferior appendages approximately equal in length to preanal 
appendages and inclined dorsoposterad; each with first segment armlike, second segment about 1/4 as long as first and bearing many short teeth apically.

Female. Wings (Fig. 5), anterior wing with forks 1-5, with forks 3 and 4 petiolate; posterior wing with forks 1, 2, 5. Abdomen without midsternal processes. Genitalia: Segment IX with tergum hoodlike, with pair of broad processes almost completely fused together, having posterior margin broadly rounded with minute mesal notch in dorsal view; tergum IX triangular in lateral view; bearing small pair of ventrolateral appendages, each located slightly ventroposterad from small glabrous lateral groove.

Distribution and habitat. High altitude brooks in the eastern evergreen forests of Madagascar.

Etymology. Afro-from Africa; Greek, rheithron, current, stream; gender masculine.

\section{Afrorheithrus fallax sp. nova}

(Figures 2, 3, 5-15, 29)

Material. Holotype $o^{\star}$ (pinned) [USNM], MADAGASCAR, Fianarantsoa Prov., 7 km W. Ranomafana, 1,100 m, 22-31.X.1988, W. E. Steiner, flight intercept-yellow pan in Malaise trap, island in stream, montane rainforest. Paratype +9 (pinned) [USNM], same data as holotype. $10^{x}$ (in alcohol) [NMPC], MADAGASCAR, Fianarantsoa Prov., $2.5 \mathrm{~km}$ SE Ranomena (Iranomena), brook, tributary of Tatamaly River, 47²4'11" E, $21^{\circ} 29^{\prime} 36^{\prime \prime}$ S, approx. 1,050 m a.s.1., 9.II.2000, P. Chvojka leg., swept along rapid brook in rain forest.

Diagnosis. Afrorheithrus fallax differs from A. mirus by having preanal appendages more slender in lateral view, and segment $X$ petiolate in lateral view, and with apicolateral margins nearly straight and angled toward small apicomesal notch in dorsal view.

Male. Color predominately dull brown with some yellowish brown areas; anterior wings brown with flecks of beige and yellowish brown. Head, eyes dark brown, glabrous; antennal warts each bearing many light yellowish setae and few dark brown setae on anterolateral side; occipital warts with many long dark brown anterolateral bristles, and some light yellowish, posteromesal setae; postorbital warts with dark brown setae. Frons yellowish brown with notch between bases of antennae and anterolateral warts each triangular and adjacent to eye; hypomedial warts small, nearly circular. Antennae, scapes nearly cylindrical, each equal in length to diameter of eye and bearing many dark brown setae. Maxillary and labial palps with dark brown setae. Pronotum mostly yellowish brown, medial warts with combination of yellowish setae and dark brown setae; median area, between medial warts, recessed, dark brown with slender light brown stripe; and lateral warts with many dark brown setae and some yellowish setae. Mesonotum, scutum with anterior portion having pair of medial stripes composed of many light yellowish microtrichia; scutellum yellowish brown with many yellowish setae throughout and some dark brown setae in posterolateral area. Thorax with pleura and fore coxae yellowish brown, middle coxae brown and hind coxae dark brown; mesepimeron each with pleural wart bearing conspicuous tuft of white setae. Scapes, each $0.6 \mathrm{~mm}$. Anterior wings each $13 \mathrm{~mm}$, and posterior wings each $11.5 \mathrm{~mm}$.

Male genitalia (Fig. 7-12): Segment IX, anterior margin of each pleuron bearing rounded projection just above sternum in lateral view. Preanal appendages extended posterad with lateral margins nearly straight and parallel, but slanted slightly mesad in dorsal view; each appendage thumblike and $2 \mathrm{X}$ as long as basal width in dorsal view; mid section nearly uniform in height, majority of dorsal margin nearly straight and horizontal, but apical 1/4 curved slightly ventrad in lateral view. Segment X capitate with dorsal margin nearly straight, inclined slightly dorsad, apical portion curved strongly ventrad in lateral view; maximum width at $2 / 3$ length, lateral margins curved, and apex nearly right-angled with small mesal notch in dorsal view. Inferior appendage thumblike and extended dorsoposterad in lateral view. Phallus extended almost as far as segment X; curved irregularly, middle of dorsal margin convex and ventral margin concave, maximum height at midlength, about $1.5 \mathrm{X}$ greater than height of apical portion in lateral view. 

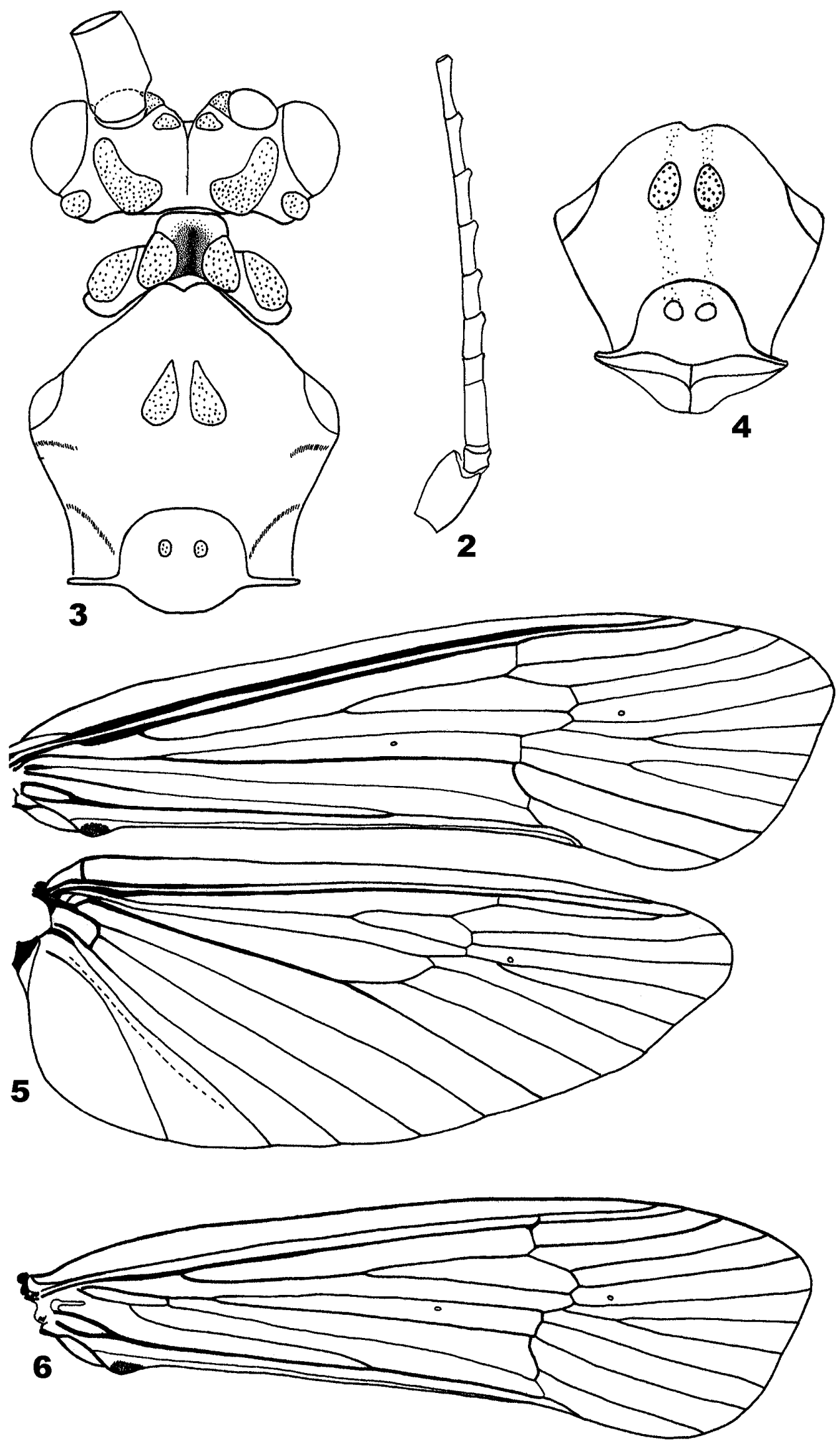

FIGURES 2-6. Figs. 2-3. Afrorheithrus fallax: 2. male antenna, right lateral. 3. female head, pronotum and mesonotum, dorsal. Fig. 4. A. mirus, male mesonotum, dorsal. Figs. 5-6. A. fallax: 5. female wings. 6. male, anterior wing. 

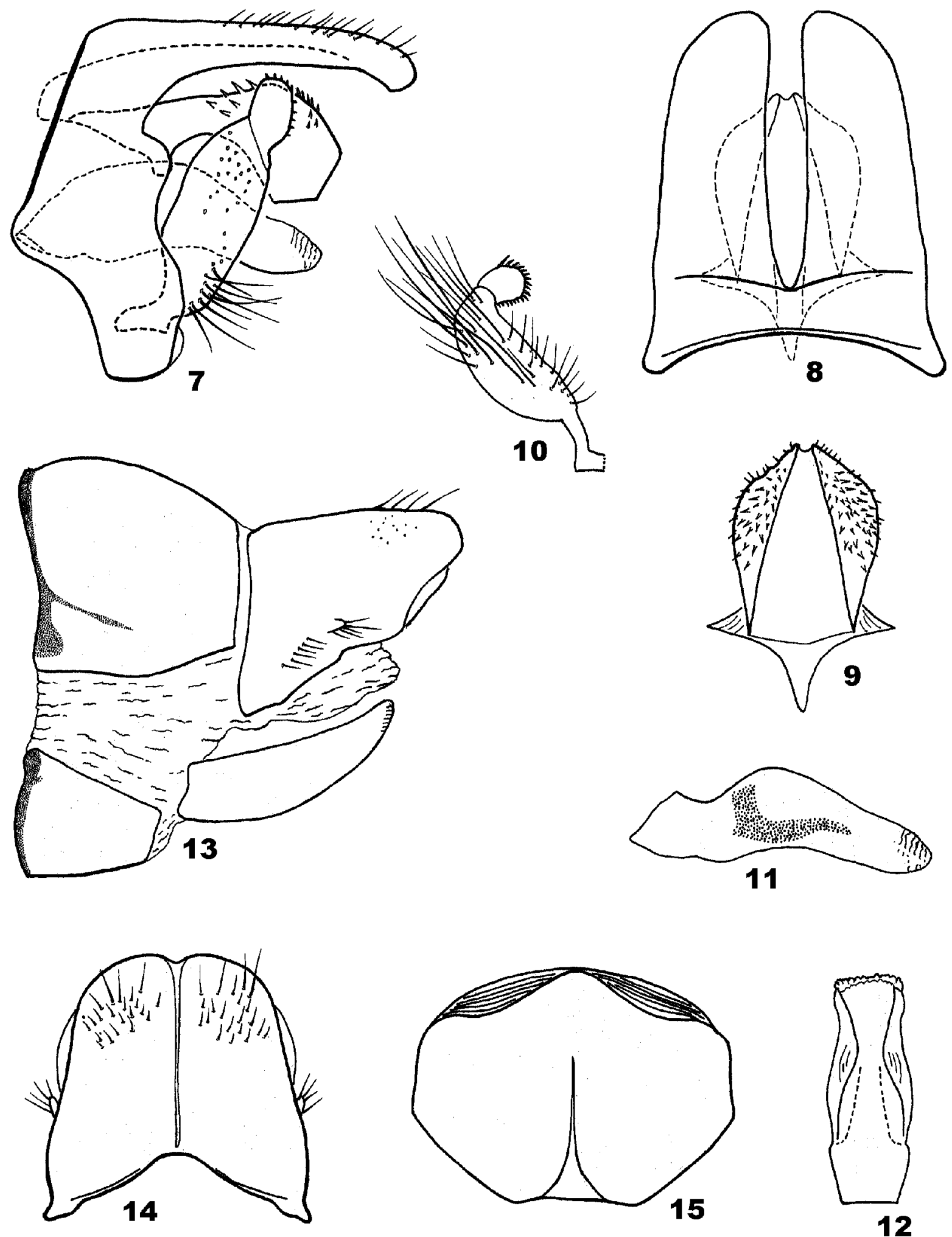

FIGURES 7-15. Afrorheithrus fallax. Figs. 2-3. male: 7. genitalia, lateral. 8. segments IX and X, dorsal. 9. segment X, dorsal. 10. left inferior appendage, posteroventral. 11. phallus, lateral. 12. phallus, ventral. Figs. 13-15. female: 13. segments VIII and IX, lateral. 14. segment IX, dorsal. 15. segment IX, ventral. 
Female. Color similar to that of male. Scapes each $0.7 \mathrm{~mm}$. Anterior wings each $20 \mathrm{~mm}$, posterior wings each $16.5 \mathrm{~mm}$. Genitalia (Figs. 13-15): Segment IX tergum triangular with blunt apex in lateral view; Ushaped with posterior margin slightly bilobed, with each lobe broadly curved in dorsal view; lateral appendages lobiform and short, each having small, shallow, glabrous, dorsolanteral cavity. Segment IX sternum, somewhat pentagonal, posterior margin with lateral portions nearly straight and middle half rounded triangular in ventral view. Spermathecal sclerite about 2.5 times as long as wide.

Egg mass. Nearly spherical, gelatinous, dry, about $3.5 \mathrm{~mm}$ in diameter. Prior to clearing the female abdomen, the egg mass was attached to the egg pouch.

Etymology. Latin: fallax, elusive, deceiving.

\section{Afrorheithrus mirus sp. nova}

(Figures 4, 16-22, 29)

Material. Holotype $0^{x}$ (pinned) [NMPC], labeled: "MADAGASCAR, Mus. Pragense". [Specimen from the collections purchased from Lamberton (Antananarivo) in the early 1900s.] Paratypes $10^{\star} \& 1$ 우 (in alcohol) [MNHN], MADAGASCAR, Andringitra National Park, tributary of the Sahavatoy (Manampatrana river basin), 46.58.30 E, 22.12.50 S, 1210 m, (WWF camp \#3, 22.XI.1993, leg. F.M. Gibon, at light trap in forest.

Diagnosis. Afrorheithrus mirus differs from A. fallax by having preanal appendages broader in lateral view, and segment $\mathrm{X}$ clavate almost square with apicolateral margins rounded and apex with a pair of short rounded triangular mesal processes in dorsal view, and wedge-shaped in lateral view.

Male. General color light brown; anterior wings mostly brown, each with proximal two-thirds yellowish brown, distal one-third greyish brown, proximal portion much lighter than distal portion. Posterior wings dull grey. Head with eyes nearly black and glabrous; antennal warts bearing light brown setae; occipital warts bearing mostly light brown setae and some brown setae laterally; postorbital warts bearing dark brown setae. Frons with anterolateral warts bearing brown setae; hypomedial warts with whitish setae and smaller than anterolateral warts. Pronotum brown, medial and lateral warts covered with combination of light and dark brown setae, with recessed area between medial warts dark brown. Mesonotum with scutal and scutellar warts bearing thin white setae. Legs mostly yellowish brown, with hind coxae and hind femora dark brown. Mesepimeron each with pleural warts bearing whitish setae. Setal warts of head, pronotum, and mesonotum generally similar to those of $A$. fallax, except mesoscutal warts nearly elliptical and tapered slightly anteriorly. Anterior wings each $14.2 \mathrm{~mm}$, and posterior wings each $12.2 \mathrm{~mm}$. Abdomen without midsternal processes.

Male genitalia (Fig. 16-19). Segment IX, anterior margin of each pleuron bearing rounded triangular process just above sternum in lateral view. Preanal appendages, each having basal three-fourths with lateral margin angled slightly towards subapex, and distal fourth with apicolateral margin angled more strongly toward rounded triangular apex in dorsal view; triangular with horizontal length $2 \mathrm{X}$ vertical height at base, ventral margin slightly irregular, dorsal margin nearly straight, apex rounded triangularly in lateral view. Segment X, rounded triangularly, with dorsal margin nearly straight and horizontal, ventral margin inclined ventroposterad, apicodorsal margin rounded and emarginated, apex rounded and extended posteroventrad in lateral view; rounded square with base tapered slightly, apicolateral margin rounded, apical margin with a pair of short, rounded, mesal triangular processes in dorsal view. Inferior appendage thumblike and extended dorsoposterad in lateral view. Phallus extended as far as subapex of segment X, dorsal margin of apical portion nearly straight and inclined slightly ventral in lateral view.

Female. Color similar to male. Scapes each $0.74 \mathrm{~mm}$. Anterior wings each $19 \mathrm{~mm}$, and posterior wings each $15 \mathrm{~mm}$. Genitalia (Fig. 20-22): Segment IX tergum triangular, tapered toward rounded apical lobe in lateral view; U-shaped with posterior margin bilobed broadly in dorsal view; lateral appendages lobiform. Spermathecal sclerite $3 \mathrm{X}$ as long as wide. 
Remarks. In a preliminary report of the caddisfly fauna of Madagascar (Gibon et al. 1999), the paratype was considered to be a possible odontocerid or atriplectidid

Etymology. Latin: mirus, surprising.

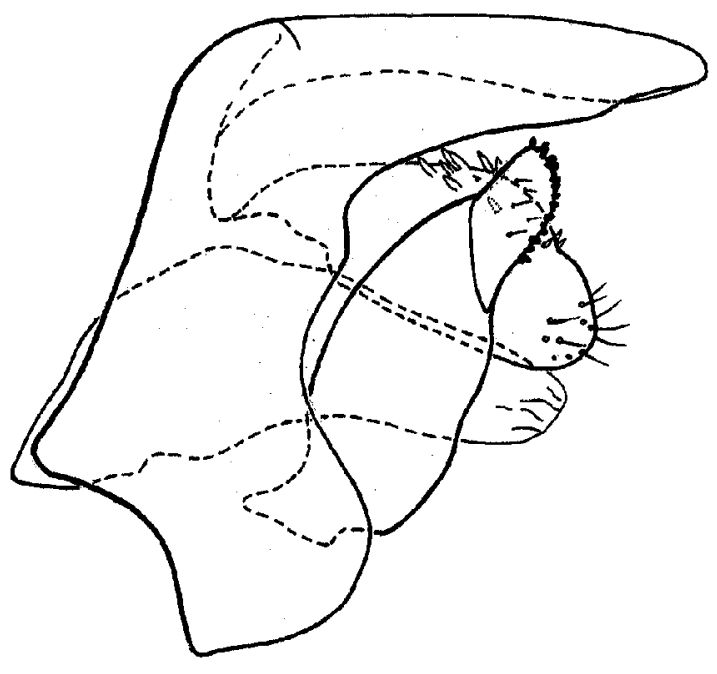

16
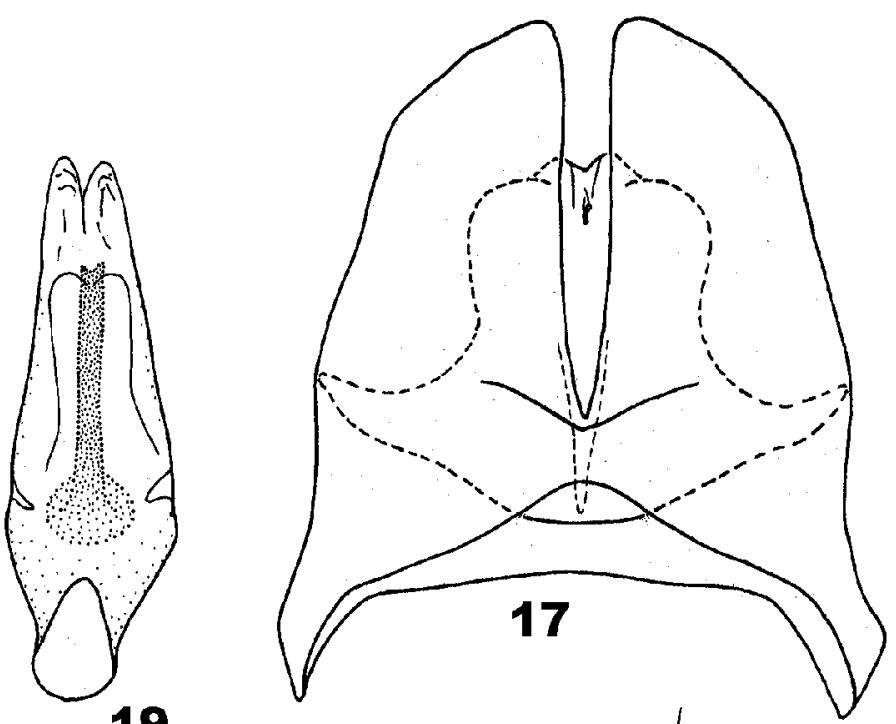

19
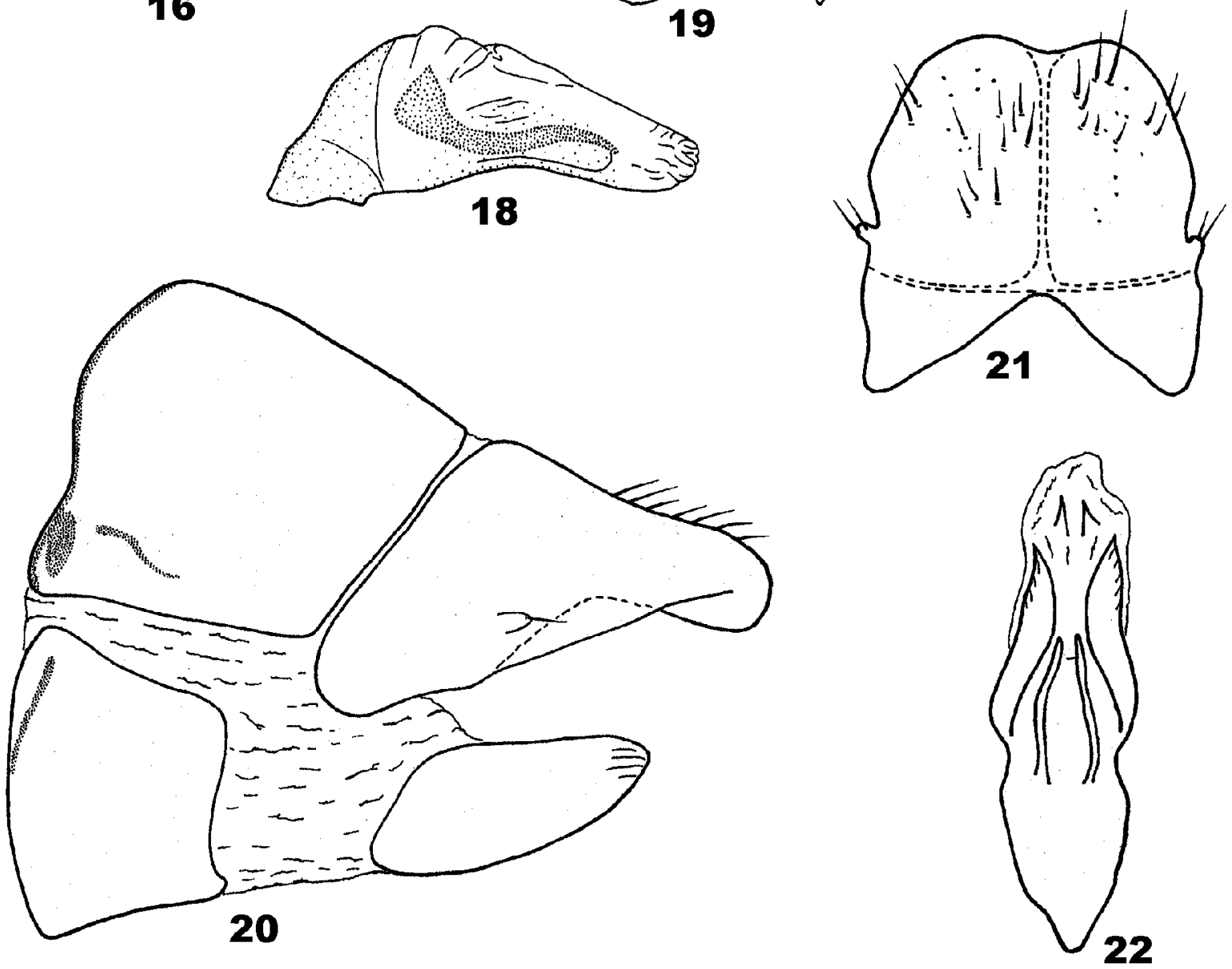

FIGURES 16-22. Afrorheithrus mirus. Figs. 16-19. male: 16. genitalia, lateral. 17. segments IX and X, dorsal. 18. phallus, lateral. 19. phallus, ventral. Figs. 20-22. female: 20. segments VIII and IX, lateral. 21. segment IX, dorsal. 22. spermathecal sclerite, ventral. 
Material. Holotype $0^{\star}$ (in alcohol) [NMPC], MADAGASCAR, Toamasina Prov., 4 km E Amboditafonana,

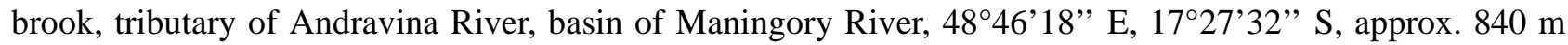
a.s.l., 28-29.I.2000, P. Chvojka leg., swept along slow-flowing brook in rain forest. Paratype ${ }^{\star}$ (in alcohol) [NMPC], same data as holotype.
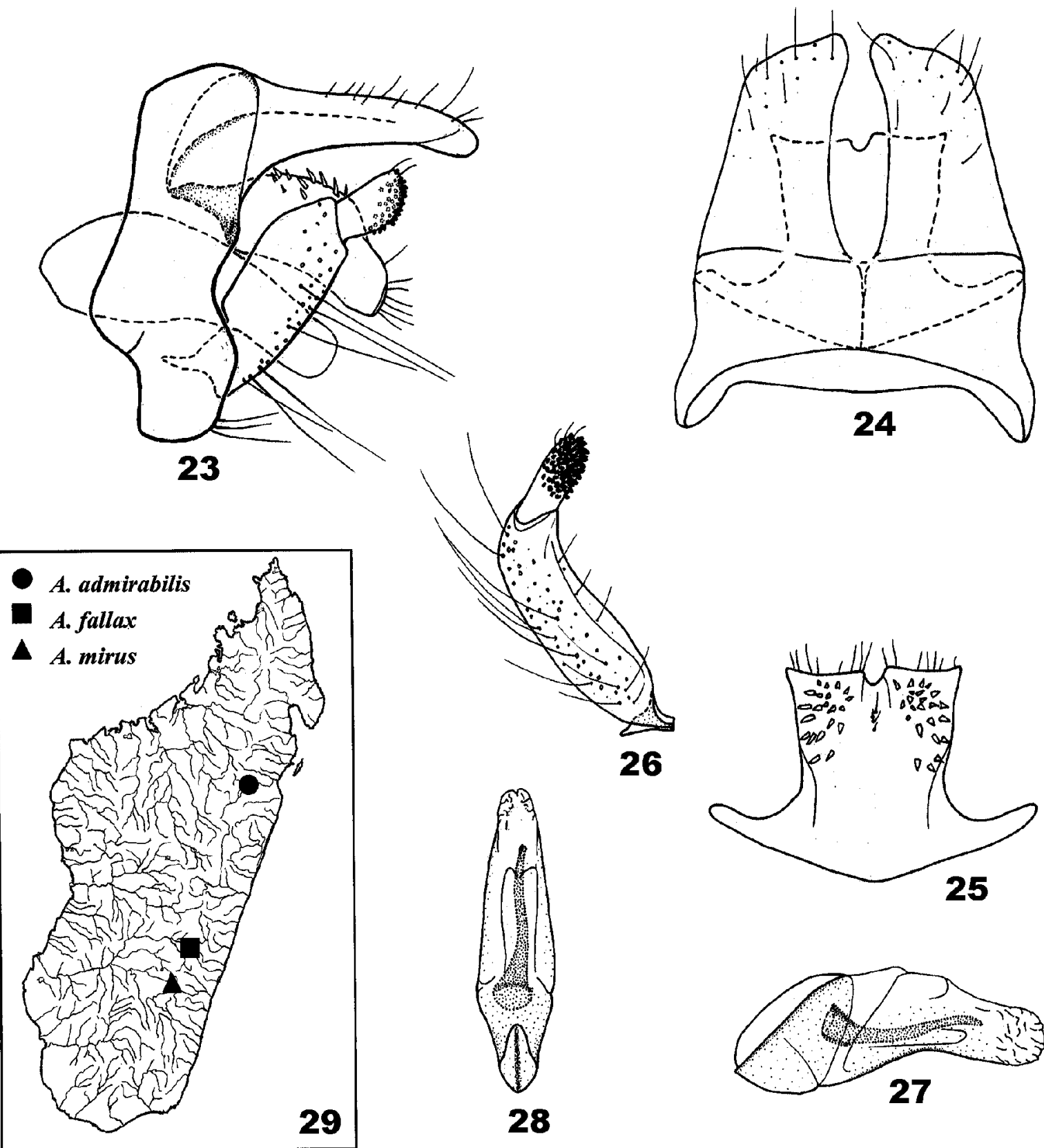

FIGURES 23-29. Figs. 23-28. Afrorheithrus admirabilis, male: 23. genitalia, lateral. 24. segments IX and X, dorsal. 25. segment X, dorsal. 26. left inferior appendage, posteroventral. 27. phallus, lateral. 28. phallus, ventral. Fig. 29. Map showing collection sites of Afrorheithrus species.

Diagnosis. This species differs from A. fallax and A. mirus by having preanal appendages obliquely truncated, with apices converging in dorsal view, and with dorsal surface slightly lower than dorsum of segment 
IX in lateral view; and segment $\mathrm{X}$ truncated apically and lateral margins nearly straight and parallel, but diverging slightly apically.

Male. Color generally brown; anterior wing brown with basal two-thirds light brown (based on holotype in alcohol, some setae lost). Head, eyes brown, glabrous; antennal warts each bearing light yellowish brown setae; occipital warts each with mostly light brown setae and few dark brown setae anteriorly; and postorbital warts with dark brown setae. Frons yellowish brown; vertex with notch between bases of antennae; anterolateral warts each bearing dark brown setae, triangular with lateral margin adjacent to eye; hypomedial warts each bearing light yellowish brown setae, except for one dark brown seta, small, nearly circular. Antennae bearing many short light brown setae; scapes each $0.6 \mathrm{~mm}$, nearly cylindrical, equal in length to diameter of eye and bearing mostly light brown and few dark brown setae laterally. Maxillary and labial palps with mixture of light and dark brown setae. Pronotum mesal surface area dark brown and concave, two light brown areas adjacent to median warts, and two dark brown areas adjacent to lateral warts; median warts bulbous, light brown and bearing mostly light brown setae; lateral warts dark brown and bearing light and dark brown setae. Mesonotum, with warts similar to those in Fig. 4; scutum mostly dark brown, with middle slightly lighter in color, bearing light brown setae, posterior mesal area apparently bearing yellowish brown microtrichia; scutellum light brown, much lighter than scutum, bearing mostly light brown setae. Thorax with pleura, fore and middle coxae brown, hind coxae slightly dark brown. Anterior wings each $12.7 \mathrm{~mm}$, and posterior wings each $11.5 \mathrm{~mm}$.

Male genitalia (Figs. 23-28): Segment IX anterior margin of each pleuron with short, rounded projection just above sternum in lateral view. Preanal appendages nearly straight, horizontal and fingerlike with apical fifth bent slightly ventrad; lateral margins nearly straight and inclined slightly mesad, apices obliquely truncated, apicomesal angles rounded-triangular and converging in dorsal view. Segment X almost square, widened slightly apically, apicolateral angles acute, apical margin truncate with small rounded mesal notch in dorsal view. Inferior appendage thumblike and extended dorsoposterad in lateral view. Phallus extended as far as subapex of segment $\mathrm{X}$; ventral and dorsal margins slightly sinuate, basal two-thirds about $1.8 \mathrm{X}$ greater in height than apical portion in lateral view.

Etymology. Latin: admirabilis, admirable.

\section{Acknowledgments}

We wish to thank Oliver S. Flint Jr., Smithsonian Institution, National Museum of Natural History, for providing specimens for examination and especially for his encouragement in the completion of this work; Donald S. Chandler, University of New Hampshire, for reviewing the manuscript; Steven M. Goodman, World Wildlife Federation, for supporting our participation in the expeditions of the Andringitra and Marojezy Forests; and the Ministry of Culture of the Czech Republic (project No. MK00002327201) for supporting the work of Pavel Chvojka.

\section{References}

Cowley, D.R. (1978) Studies on the larvae of New Zealand Trichoptera. New Zealand Journal of Zoology, 5, 639-750.

Flint, O.S. Jr, Holzenthal, R.W. \& Harris, S.C. (1999) Catalog of the Neotropical Caddisflies (Insect: Trichoptera). Ohio Biological Survey, Columbus, Ohio, 239 pp.

Gibon, F.-M., Andriambelo, Z. \& Randriamasimanana, D. (1999) A study of the diversity and richness of the Malagasy Trichoptera. In: H. Malicky \& P. Chantaramongkol (Eds.) Proceedings of the $9^{\text {th }}$ International Symposium on Trichoptera. Chiang Mai University, Chiang Mai, pp. 123-124.

Hudson, G.V. (1904) New Zealand Neuroptera. West, Newman \& Company, London, 98 pp., 11 plates.

Mosely, M.E. \& Kimmins, D.E. (1953) Trichoptera of Australia and New Zealand. British Museum of Natural History, 
London, $550 \mathrm{pp}$.

Neboiss, A. (1977) A Taxonomic and Zoogeographic Study of Tasmanian Caddis-flies. Memoirs of the National Museum of Victoria, 38, 1-208, 3 plates.

Neboiss, A. (1991) Trichoptera. In: I.D. Neumann, The insects of Australia, $2^{\text {nd }}$ ed. Division of Entomology Commonwealth Scientific and Industrial Research Organization, Melbourne University Press, Melbourne, pp. 787-816.

Parker, C.R. \& Wiggins G.B. (1987) Revision of the caddisfly genus Psilotreta (Trichoptera: Odontoceridae). Royal Ontario Museum. Life Sciences Contributions, 144, 1-55.

Schmid, F. (1955) Contributions à la connaissuance des Trichoptères néotropicaux. Mémoires de la. Société vaudoise des Sciences Naturelles, 11, 117-160.

Schmid, F. (1964) Contribution a l'etude des trichopteres neotropicaux V. Tijdschrift voor Entomologie, 107, 307-339.

Schmid, F. (1980) Genera des Trichoptères du Canada et des États adjacents. Les Insectes et Arachnides du Canada, 7 , 1-296. 